\title{
Response to antenatal HIV testing and prevention of parent to child transmission: an experience in a tertiary hospital in Chitwan, Nepal
}

S.M. Pokharel ${ }^{1}$, H. Abbas², A. Ghimire ${ }^{3}$

${ }^{1}$ Assistant Professor, ${ }^{2,3}$ Intern, Department of Obstetrics \& Gynecology CMS, Bharatpur.

\begin{abstract}
The antenatal screening of HIV in all women is becoming an integral part of routine antenatal checkup in Nepal, by prevention of parent to child transmission (PPTCT) program. The aim was to analyze the response to implementation of PPTCT program in a peripheral hospital and to study the involvement of husbands for counseling and testing. Data of 3360 women attending the antenatal clinic from January 2010 to December 2010. Data of husband counseling and testing was also analyzed. Acceptability of the test after pretest counseling is $99 \%$. Women attended post test counseling and collected reports in 58.6\%. Sero prevalence of HIV was $0.73 \%$ of which $62.5 \%$ came for post test counseling. Only $10 \%$ of husbands of total antenatal cases came for counseling of which $6.6 \%$ got tested. The acceptability of the test after pretest counseling is satisfactory but the follow up for the post test counseling is to be improved. There is need to enhance male involvement to make husband friendly antenatal clinic.
\end{abstract}

Key words: HIV, PPTCT (Prevention of parent to child transmission), antenatal check up.

\section{Introduction}

Prevention of parent to child transmission (PPTCT) Of HIV is a national program, which is being implemented in hospital. This is the most successful program being implemented against HIV. This program not only helps to prevent parent to child transmission in sero positive population but also creates awareness about HIV in large number of couples attending antenatal clinics. It also gives the opportunity to identify infected partners. The antenatal screening of HIV is becoming an integral part of routine antenatal check

Correspondence: .M. Pokharel

Email: sunilmani@hotmail.com up. Our aim is to study the response to the implementation of PPTCT as well as the involvement of husbands for counseling and testing in the tertiary hospital in Chitwan.

\section{Materials and methods}

This study was conducted in College of Medical Sciences, Bharatpur. The data over a period of 1 year from January 2010 to December 2010 was analyzed. Total antenatal registrations were 3360 among which 2946 underwent pretest counseling and antenatal screening for HIV. 
S.M. Pokharel et al. Response to antenatal HIV testing and prevention of parent to child transmission........

\section{Results}

Total Antenatal

3360

Antenatal cases underwent

HIV testing

$2946 \quad 99 \%$

Women who underwent counseling

$172658.6 \%$

Total husbands counseled

$290 \quad 10 \%$

Total husbands tested

$194 \quad 6.6 \%$

Total HIV positive mothers

$0.73 \%$

HIV mothers who attended post

test counseling

$14 \quad 62 \%$

Women referred to higher centres

Positive women who never attended

post test counseling

Husbands found positive

There were 3360 new antenatal registrations. Among them, after pretest counseling 2946 i.e. almost $99 \%$ of the women underwent HIV testing. 22 patients were found seropositive i.e. $0.73 \%$. Total 2946 women came for post test counseling i.e. $58.60 \%$ and among 22 seropositive women only 14 came back for post test counseling and report collection i.e. 62\%. All HIV positive mothers were referred to higher centers. Among the seropositive women, remaining 8 never attended post test counseling, so we don't know whether they delivered in private hospital or at home. Total 290 husbands were counseled i.e. $10 \%$ of the total women attending the antenatal clinic. Among the husbands counseled only 194 underwent HIV testing. Among the total 22 positive only 12 husbands were tested for HIV and 10 were found to be positive.

\section{Discussion}

This data represents the implementation and the response to the prevention of parent to the child transmission program for HIV in a tertiary hospital

\{CMS, TH Bharatpur). The women are coming from poor socioeconomic class with poor literacy rate having low awareness of the disease. This program is effectively creating awareness regarding testing of HIV among this class, hence the rate of testing is almost 99 $\%$. This suggests that PPTCT is becoming an integral part of effective and routine antenatal care. In other studies the rate of testing is $86-90 \%^{1-3,5,8}$

When we see post test counseling among all, 58.6\% women came for post test. In 22 seropositive women only 14 i.e. $62 \%$ women came for post test counseling, so this is the area where more of concentration is needed. The low percentage of women who attended post test counseling to collect report is due to various reasons including fear, ignorance, and poor education. ${ }^{4}$, 5,7,10. When we compare it with other studies it is still better figure. In other studies post test counseling is up to $30 \%$, in central institute itself., ${ }^{1,6}$

Total number of husbands counseled for HIV testing was 290 i.e. $10 \%$ of total women. Among them only 194 accepted testing. This suggests that the second area of concentration needed is participation of husbands. Practically the husbands are not always accompanying women in the antenatal clinics. Secondly there is an attitude of why I need to be tested if my wife is pregnant. Thirdly, if the husband had any risk behavior he refused to undergo the test due to fear of diagnosis. ${ }^{9}$ In our society the rearing of a child is still considered to be a job of a woman. Even otherwise husband participation in antenatal clinics is low. In public hospitals it is not a practice for husband and wife to attend antenatal clinics together. Hence there is no opportunity for the doctor or the counselor to talk to the husband. 


\section{Conclusion}

The acceptance rate of HIV testing by women is satisfactory. It is becoming almost an integral part of routine antenatal clinic. But the post test counseling needs to be improved. Almost all seropositive women should be cured under NEVIRAPINE treatment. There is a possibility of women delivering at other hospitals. Therefore a follow up of such women and proper documentation is needed with inter-sectoral coordination between public and private hospitals. The hospital should be connected to a husband friendly hospital. There is a need to enhance male involvement in antenatal clinics in the public sector hospitals. After all antenatal clinics are an effective opportunity for health care providers to create awareness of HIV among the larger community. ${ }^{9}$ Apart from prevention of transmission of HIV to the child, it provides a great opportunity for the parents themselves in containing the disease. Prevention is the cure and antenatal clinic is the best opportunity to educate.

\section{References:}

1. N. Maitra, AB. Kavishvar, A. Dinkar et al. Antenatal HIV testing. J Obstet Gynaecol India 2006;56:56-8

2. DM Patrick, DM Money, J. Forbes et al. Routine prenatal screening for HIV in a low-prevalence setting. CMAJ 1998;159:942-7

3. DM. Gibb, SE. MacDonagh, R.Gupta et al. Factors affecting uptake of Antenatal HIV testing in London: results of a multicentre study. BMJ 1998;316:259-61
4. L. Samson, S. King. Evidence-based guidelines for universal counseling and offering of HIV testing in pregnancy in Canada. CMAJ 1998; 158:1449-57.

5. WM. Simpson, FD. Johnstone, DJ. Goldberg et al. Antenatal HIV testing: assessment of a routine voluntary approach. BMJ 1993; 318:1660-1.

6. TA. Duffy, CD. Wolfe, C. Vardenet al. Women's knowledge and attitudes, and the acceptability of voluntary antenatal HIV testing. Br J Obstet Gynaecol India 1998; 105:849-54.

7. Revised recommendations for HIV screening of pregnant women. MMWR Recomm Rep. 2001; 50:6385.

8. SA Nichols, MP Bhatta, Lewis et al. Prenatal HIV counseling, testing, and antiretroviral prophylaxis by obstetric and family medicine providers in Alabama. Am J Med Sci 2002; 324:305-9.

9. C Kilewo, A Massawe, E Lyamuya et al. HIV counseling and testing of pregnant women in sub-Saharan Africa: experiences from a study on prevention of mother-tochild HIV-1 transmission in Dar es Salaam, Tanzania. J Acquir Immune Defic Syndr 2001; 28:458-62.

10. M. Manzi, R. Zachariah, R. Teck et al. High acceptability of voluntary counseling and HIV- testing but unacceptable loss to follow up in a prevention of mother-to-child HIV transmission programme in rural Malawi: scaling-up requires a different way of acting. Trop Med Int Health 2005; 10:1242-50. 